\title{
THE TECHNIQUE OF HYPOTHERMIC PERFUSION
}

\author{
BY \\ P. J. MOLLOY* AND R. I. LINDFIELD \\ From the Thoracic Surgical Unit, Guy's Hospital, London
}

(RECEIVED FOR PUBLICATION OCTOBER, 1961)

This report is to describe the machine for extracorporeal circulation in use at Guy's Hospital, to discuss the technique of preparing and assembling the circuit, and to indicate the method of hypothermic perfusion.

\section{The Machine and Extracorporeal Circuit}

The machine described is in commercial production although the perfusions, to date, were performed with the prototype described by Ross (1960a). The extracorporeal circuit is mounted on the front of the machine (Fig. 1) under the vision of the perfusionist and comprises:

Coronary suction reservoir (A) into which all wound and coronary sinus blood is returned by suction from a horizontally mounted de Bakey pump (B). This reservoir contains a filter of six coarse stainless steel meshes and one fine mesh separated by $\frac{1}{2}$ in. nylon spacers, mounted on a central rod suspended from the cap of the reservoir. This filter is to defoam blood and trap any particles of tissue, fat, or calcium which may return to the circuit. The meshes are coated with silicone antifoam (MS "A "), the only place in the circuit where this substance is used. On the cover of the reservoir is an entry port for the recirculating lead $(C)$ which is used for mixing drugs and maintaining blood temperature during periods of circulatory arrest. There are four 3/16 in. holes drilled in this disc to receive the giving set nozzles used for priming the circuit. The bottom disc is pierced by a $\frac{1}{2}$ in. hole to receive a lead of $\frac{1}{2}$ in. "tygon" (D) connecting to the venous reservoir (E). This lead is interrupted by a Y piece connected to an ancillary circuit $(F)$ to bleed the machine should return become embarrassingly profuse.

The venous reservoir (E) is a cylinder of clear Perspex $7 \mathrm{~cm}$. in internal diameter with removable top and bottom cover plates which are approximated by rubber $\mathrm{O}$ rings, rigid rods, and bolts. This makes for ease in cleaning and removes crevices where stale blood may remain and give rise to pyrogenic reactions in subsequent patients. The lower cover plate is drilled with two holes, one $\frac{1}{2}$ in. in diameter connected to the coronary suction reservoir and one $\frac{3}{8}$ in. in diameter connected to the venous return lead from the patient. The connexions are stainless steel and are sealed by $\mathbf{O}$ rings which are compressed by flanges engaging in lugs on the under surface of the cover plate. All blood from the patient is returned to the circuit and blood loss is kept to a minimum. The upper cover plate has a 3/16 in. hole for placing the thermometer to monitor mixed venous blood temperature, a $\frac{3}{8}$ in. hole to receive the left atrial vent, and a 5/16 in. hole to prevent pressure build-up in the venous reservoir.

Blood is returned to this reservoir by gravity drainage, the patient being 14 in. above the machine blood level. This reservoir acts as a debubbling chamber and its level is maintained above the top of the entry port into the oxygenating chamber to which it is clamped, a blood-tight seal being effected over an $\mathrm{O}$ ring seated in a recess on the oxygenator end plate.

The oxygenator chamber $(G)$ is a cylinder of clear Perspex $12 \mathrm{~cm}$. in diameter and $50.7 \mathrm{~cm}$. long, closed by two removable end plates bolted together outside the cylinder. The end plates are drilled centrally to support a nylon bearing which is itself drilled $2 \mathrm{~mm}$. eccentrically to support the spindle on which the discs are mounted. This allows more of the disc surface to enter the blood without increasing the priming volume. The venous end plate is drilled at its lower edge to receive the venous reservoir as described above. Blood flows into the chamber, is picked up as a film on the discs, and oxygenated. The discs rotate at $\mathbf{1 2 0}$ or 40 revolutions per minute, the slower speed being employed during preparation and periods of circulatory arrest to minimize blood trauma. Provision is made for a bracket on which a second oxygenator can be mounted in parallel to provide sufficient oxygenating surface for full normotharmic flows.

The arterial end plate has two 3/16 in. holes drilled to receive the oxygen leads, two hollow rods which traverse the full length of the chamber and have multiple perforations. Oxygen is supplied by a lead from the cylinders $(\mathrm{H})$ after bubbling through saline. 

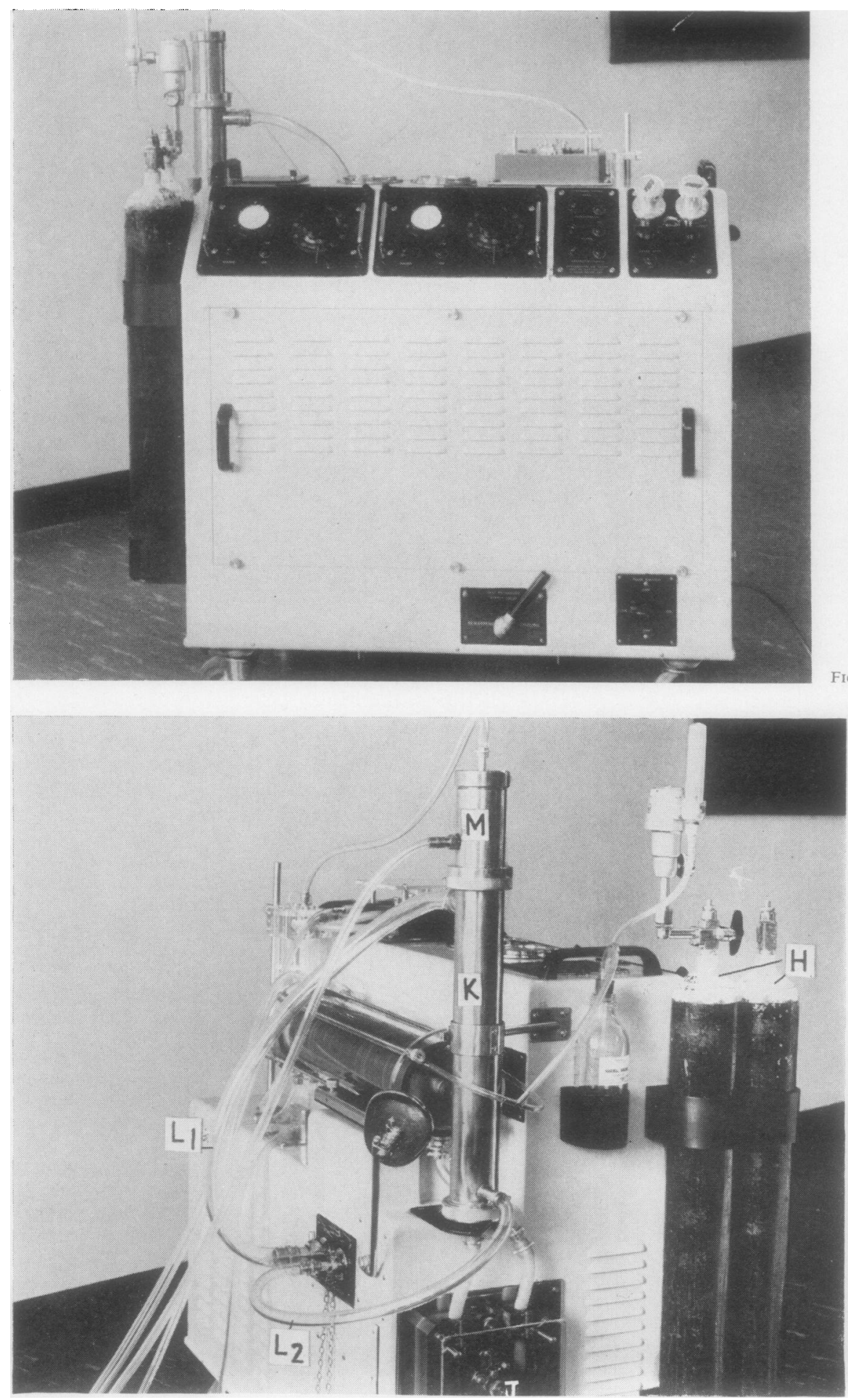


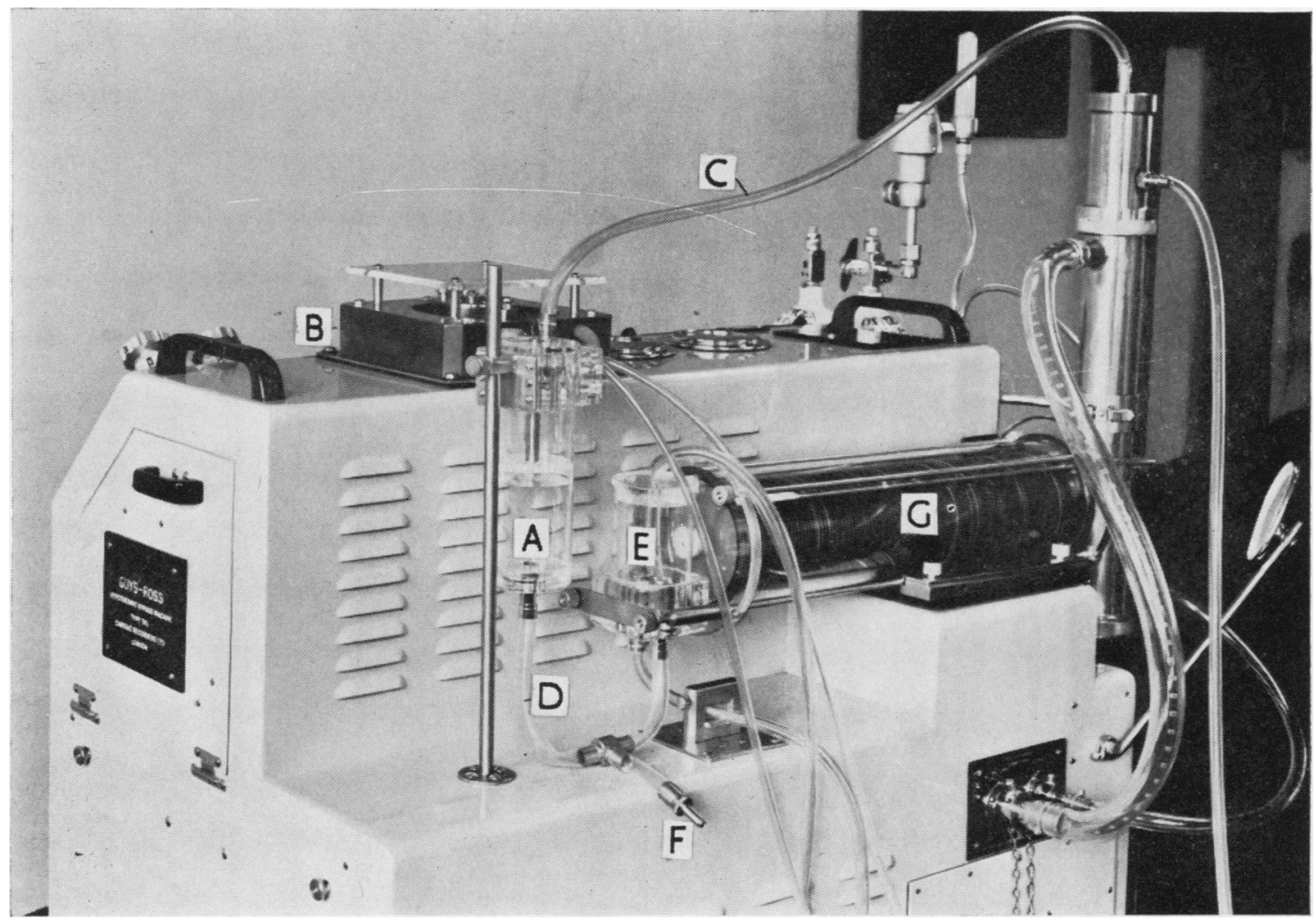

FIG, 1 (3)

Fig. 1.-This figure shows the machine from different aspects. (1) From perfusionist's side. (2) From arterial pump end. (3) !From reservoir end. A, Coronary suction reservoir; B, suction pump of de Bakey type; C, recirculating lead; $\mathbf{D}$, connecting tube; $\mathbf{E}$, venous reservoir; F, ancillary bleeding-off lead; G, oxygenator chamber; $\mathbf{H}$, oxygen supply; J, arterial pump of de Bakey type; K, heat exchanger; $L_{1}-L_{2}$, inlet and outlet leads for heat exchanger fluid; $M$, filter chamber.

The discs are flat, stainless steel plates $10.8 \mathrm{~cm}$. in diameter and $1 \mathrm{~mm}$. thick. They are separated from each other by $4 \mathrm{~mm}$. nylon spacers. There are 100 discs in an adult lung and 60 in the smaller cylinder used for children. When $2.4 \mathrm{~cm}$. of disc perimeter is dipping in the blood 126.7 sq. $\mathrm{cm}$. of surface is exposed to the chamber atmosphere per revolution, i.e., at 120 r.p.m. 152 sq. metres is exposed per minute. Although the discs are precision made, care is taken to ensure they are wettable; no silicone or antifoam is used nor is a high polish felt desirable. The centre spindle is connected by a pulley and belt drive to a small motor mounted under cover at the arterial end of the chassis.

Blood leaves the oxygenator by a $\frac{1}{2}$ in. hole drilled in the cylinder at its most dependent point. A stainless steel connector sealed by an $O$ ring and held by flanges secured under lugs is joined to a 25 in. length of "esco" tubing of $\frac{1}{2}$ in. internal diameter which passes through the arterial pump (J) to the heat exchanger (K). The pump is a de Bakey roller type with a double arm. The heads are set to be occlusive by a central, variable wedge adjuster which is then fixed by two bolts seating on to slots in the roller arms. The heads are single, $2.7 \mathrm{~cm}$. in width. Twin heads have been abandoned as it is thought a high pressure channel may be forced into the $\mathrm{V}$ between the heads and give rise to haemolysis. The heads sweep more than half the diameter of the pump casing, thus ensuring constant occlusiveness.

From the pump blood enters the heat exchanger (K) at the bottom through a $\frac{1}{2}$ in. steel tube. Inside the cap is a space above which the blood enters 19 $5 \mathrm{~mm}$. tubes which traverse the lumen of a water jacket which itself is completely discrete from the blood (Fig. 2). Tubes $\left(\mathrm{L}_{1}\right.$ and $\left.\mathrm{L}_{2}\right)$ connect the jacket to the cooling and heating units mounted under the chassis. The exchange inflow and output are at $180^{\circ}$ to each other to improve exchanger efficiency by reducing streaming effects. Blood re-collects into a single stream above the tubes and enters the filter chamber (M). This consists of a central obturator drilled from below with a $Y$ passage, surrounding which is a stainless steel fine mesh filter plate. This is contained by a stainless steel jacket with coarse perforations. The whole filter assembly is enclosed in an outer casing perforated laterally by two holes. The upper screw cap, perforated by a $\frac{3}{8}$ in. steel tube, completes the assembly. This upper take-off connects to the recirculating lead (C). The lateral holes, $\frac{3}{8}$ in. 


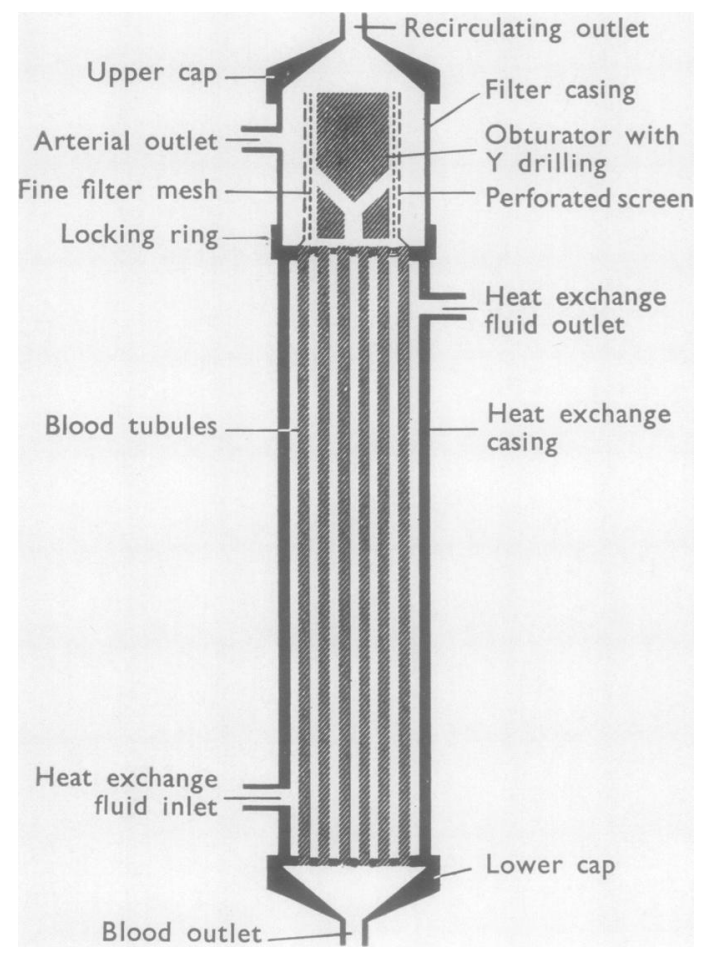

FIG. 2.-A schematic diagram of the heat exchanger to show the design and assembly. in diameter, provide exit ports for the arterial and coronary artery perfusion leads. The arterial lead is $\frac{3}{8}$ in. "tygon" and connects to a stainless steel cannula in the patient's external iliac artery. The coronary artery perfusion lead is connected via a $\frac{3}{8}$ in. $-\frac{1}{4}$ in. breakdown to a $\frac{1}{4}$ in. length of "portex" tubing to which is attached a fine cannula. The volume of flow through this lead is controlled by a gate clip.

The control panels on the other side of the machine are as shown (Fig. 3). The arterial pump unit and suction pump units are interchangeable and have a switch, indicator light, revolution counter, and variable resistance control of the "variac" pattern. These are mounted on the left of the fascia. On their right is a panel with the switches for the heating and cooling units and for the pump which circulates the appropriate fluid. Low on the chassis is mounted a lever to switch from heating to cooling as required. On the right-hand end of the fascia is a panel which includes a switch, indicator light, and variable control for the oxygenator drive. Also mounted on this panel are two Kopp type gear controls for tilting the oxygenator and clamping the venous line. On top of the machine are two large dials to show the temperature in the heating and cooling tanks. The venous clamp (devised by R. I. L.) is mounted under the venous reservoir.

The heating and cooling tanks each of 5 gallons' capacity are mounted inside the chassis under the electrical units. The heater is thermostatically controlled to $45^{\circ} \mathrm{C}$. and the cooling tank to $-8^{\circ} \mathrm{C}$. by standard heating and refrigeration units. Internal piping connects each tank to a valve which is manipulated on the outside to allow the appropriate fluid to enter the heat exchanger. The cooling fluid used is $30 \%$ ethylene glycol in water.

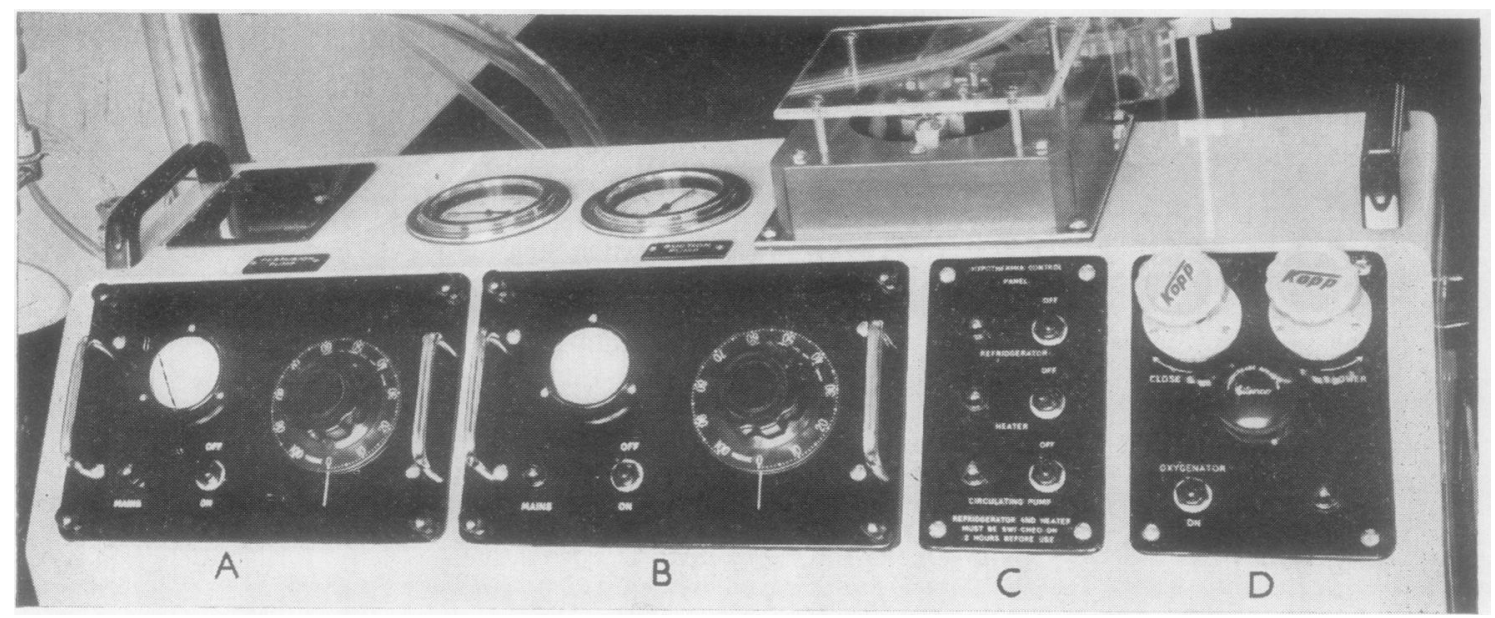

Fig. 3. -This shows the control panel of the machine and demonstrates the accessibility of controls. A., Perfusion pump control panel; B, suction pump control panel; C, hypothermia unit control panel; D, oxygenator speed control panel incorporating controls for venous clamp and oxygenator tilt. 
The whole assembly is 38 in. long, $38 \mathrm{in.} \mathrm{high,} 24$ in. wide, and weighs $550 \mathrm{lb}$. It is mounted on antistatic castors and is freely mobile.

\section{Preparation of the Circuit}

After use the entire circuit and machine are removed to a preparation room where the parts are cleaned by pumping large volumes of cold water around the circuit until most of the blood is washed away. The set is then dismounted and all plastic tubing discarded. The rubber tubing used in the arterial pump is used three times before discarding.

After thorough cleaning, all components, plastic and steel, are immersed in a $25 \%$ solution of caustic soda for a minimum of 12 hours. They are then rinsed with cold water, dilute hydrochloric acid, cold water, and distilled water in turn to remove any traces of protein material. The parts are dried separately, preferably in an air oven, and the set is then ready for reassembly. All units are assembled, care being taken not to handle surfaces which will be in contact with blood. The arterial lead $\left(5 \mathrm{ft}\right.$. of $\frac{3}{8}$ in. "tygon" tubing) is joined by a $\mathrm{Y}$ piece to the venous lead ( $5 \mathrm{ft}$. of stiff $\frac{3}{8}$ in. "portex" tubing) and the coronary sinus end of the recirculating lead $\left(2 \frac{1}{2} \mathrm{ft}\right.$. of $\frac{3}{8}$ in. "portex" tubing). The coronary sinus sucker leads (6 ft. of $\frac{1}{4}$ in. "tygon") are coiled and joined by a $Y$ piece to one of the gassing leads. If a coronary artery perfusion lead is included, a double $Y$ is used to connect all lines. The second gassing lead is connected to the free end of the left atrial vent lead ( $5 \frac{1}{2} \mathrm{ft}$. of $\frac{3}{8}$ in. " portex" tubing). All tubing is neatly coiled and bound before enfolding in a plastic bag which is then folded into two layers of linen cloth secured by adhesive tape. The set is then packed in a large clear plastic bag (Denbar Plastics) which is sealed at its end by $G$ clamps and wooden slats or in the newer bags by a zip fastener. The gassing leads emerge through a gas-tight seal at the end of the bag.

The bag is now inflated with a mixture of $10 \%$ ethylene oxide and $90 \%$ carbon dioxide until the bag is tense. The leads are then clamped and the set left for at least 18 hours to ensure sterility. Fuller details of this technique and discussion of its merits are given by Bracken, Wilton-Davies, and Weale (1960).

When required the bag is evacuated to the open air by a modified vacuum cleaner, or allowed to vent under water. Ethylene oxide is a moderately toxic gas at concentrations over $12 \%$ but is readily soluble in water to form ethylene glycol. Nitrogen, oxygen, or air may then be pumped around the circuit to remove traces of ethylene oxide, but little must remain after the high negative pressure induced on evacuation. The bag is then opened, the set is removed after separating the gassing leads and placed on the machine to which it is secured by the oxygenator bracket, the heat exchanger clamp, and the coronary reservoir stand. The recirculating lead is attached to the top of the coronary suction reservoir and secured by a metal $O$ clip, the arterial and suction pump rubbers are placed in their respective pumps (checking that the direction of flow is correct), the oxygen leads are attached and the bleeding-off bottles are assembled. The machine is then ready for use.

\section{Preparation In the Theatre}

The machine and assembly are taken to the theatre and filled with priming blood. This circuit uses 2,000 ml. of priming blood, which is collected 24-48 hours before it is required into a solution containing the sodium salt of ethylene diamine tetra-acetic acid (a chelating agent) mixed with dextrose, sodium chloride, and magnesium chloride. This solution (" edglutate") is acid ( $p \mathrm{H} \mathrm{6.85).} \mathrm{Although} \mathrm{"edglutate"} \mathrm{allows}$ collection of blood up to four to five days preoperatively it is noted that such blood after 48 hours becomes strongly acid ( $p \mathrm{H}$ 6.8-7.1) with a $\mathrm{PCO}_{2}$ of over $100 \mathrm{~mm}$. $\mathrm{Hg}$ and a bicarbonate level of less than 15 m.mol. per litre. In addition potassium levels up to $20 \mathrm{mEq}$./litre have been observed (Molloy and Griffiths, 1961 ; Molloy, 1961b). At present no active steps are being taken to correct these abnormalities before bypass begins. Several observers have reported a loss of antihaemophilic globulin, factor $V$ and diminution in platelets (Smith, Brown, Young, and Sealy, 1959; Kittle and Eilers, 1960 ; Bloom, 1961), and have commented on the lack of difficulties arising from this, but reservations are felt as postoperative haemorrhage and metabolic acidosis are occasionally severe unexplained problems.

For each $500 \mathrm{ml}$. of priming blood $20 \mathrm{mg}$. of heparin and $2 \mathrm{ml}$. of $10 \%$ calcium chloride is added to the machine. Care must be taken to add heparin first and to mix it thoroughly before adding the calcium as clotting may otherwise occur. The priming blood is recirculated with the discs turning slowly (40 r.p.m.) for mixing and oxygenation. This is done in an atmosphere of air or $100 \%$ oxygen to blow off some of the dissolved carbon dioxide. One hundred per cent. oxygenation is achieved before bypass starts.

Shortly before the surgeon is ready the pump operator scrubs and prepares the tubing. A sterile trolley is laid out with scissors, artery forceps, the special clamp for holding the tubing, a jug for hot water, and $\mathrm{a} \frac{3}{8}$ in. straight stainless steel connector. The outer linen layer is removed from the sterile pack of tubing by the pump assistant and the operator takes the inner layer. This and the plastic bag are removed with care and the tapes binding the tubing are cut away. The left atrial vent is clamped with an artery forceps as a marker and is excluded from the clamp. The venous and arterial leads are disconnected from the $Y$ piece and are joined by the $\frac{3}{8}$ in. connector. The coronary suction leads, venous lead, and arterial leads are then placed in the special clamp (devised by G. Hayes) in the appropriate grooves (Fig. 4). Blood is now pumped around the arterio-venous circuit to remove air and to fill the leads. It is important to ensure that the leads are unclamped before switching on the pumps, as a high pressure is rapidly generated. The special clamp holding the lead and the left atrial vent are then 


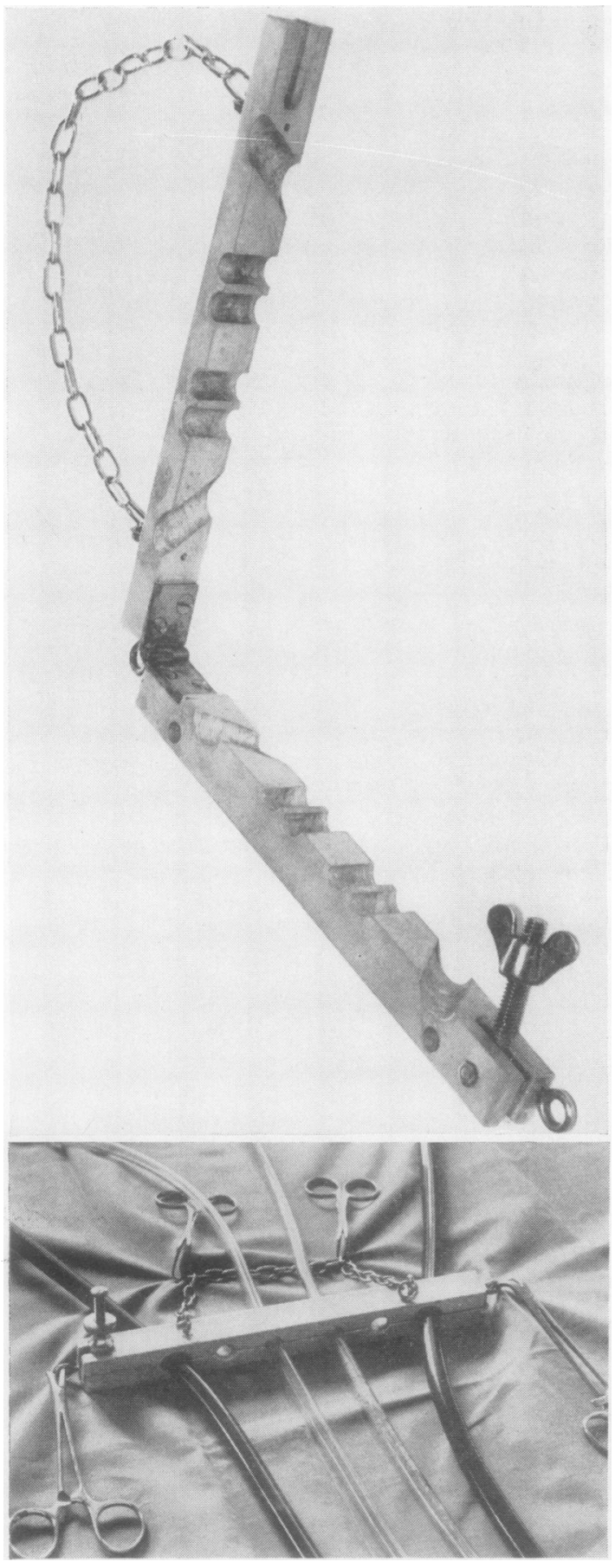

FIG. 4.-The Hayes clamp for holding the tubing at the operating table (top). The blood leads are directed headwards'and footwards respectively. The lower photograph shows the assembled tubing and method of securing the clamp to the; operating table. handed to the surgeon and the clamp is secured to the towelling. In this way the vital leads are placed simply, quickly, and securely.

\section{EXtracorporeal Technique}

When the prepared tubing is received at the table the surgeon is ready to start bypass, i.e., the external iliac or femoral artery has been exposed and cannulated, the venae cavae dissected and snared, and the heart has been explored digitally and by manometry to indicate the precise nature of the lesion. The blood-filled lines are divided between forceps, although they are clamped as well at the machine. The arterial lead is fixed to the arterial cannula in the external iliac artery. In this portion of the line a $\frac{3}{8}$ in. straight connector is inserted in which is included a Luer lock fitting controlled by a tap. This is to remove air, and to record line pressure during, and arterial pressure after, bypass.

The venae cavae are cannulated through the right atrial appendage under the control of a Rumel tourniquet, the size of these cannulae varying with the size of the patient. Usually the superior vena caval cannula is $\frac{1}{8}$ in. smaller than the inferior caval cannula. After clamping (to prevent air being sucked into the right atrium) the cannulae are connected by a $Y$ piece with a $\frac{3}{8}$ in. stem which is in turn connected to the venous lead by a short lead incorporating another $\frac{3}{8}$ in. straight connector with tap and Luer lock fitting for recording atrial pressure at the end of bypass, and for removing air before bypass. All clamps are removed from the table ends of the lines and bypass is started.

The venous lead is opened first to ensure venous flow, readily observable as a return of desaturated blood into the venous reservoir. The arterial clamp is now released, the recirculating lead clamped and the arterial pump is started at a low rate $(400-500 \mathrm{ml}$./ minute for an adult). The input and output are carefully balanced against a previously marked level. The oxygenator speed is turned to 120 r.p.m. and a mixture of $97 \%$ oxygen and $3 \%$ carbon dioxide is admitted to the chamber at 8 litres per minute. Cooling is begun when it is clear that the temperature of the priming blood $\left(15-18^{\circ} \mathrm{C}\right.$.) is inadequate to cool to the desired level $\left(28-30^{\circ} \mathrm{C}\right.$.).

Venous return and arterial output are gradually increased to allow the machine to take an increasing amount of the cardiac output. Observation of the heart in a mirror, centrally fixed in the operating light, prevents overdistension or exsanguination of the heart. A note is made of the time of onset of bypass and cooling. During this period of partial bypass oesophageal, nasopharyngeal, and mixed venous blood temperatures are monitored. The oesophageal and mixed venous temperatures fall rapidly $5-6^{\circ} \mathrm{C}$. below the nasopharyngeal. When the nasopharyngeal temperature reaches $31^{\circ} \mathrm{C}$. cooling is stopped. In an adult of average size the temperature drifts downwards for another $2-3^{\circ} \mathrm{C}$. This degree of cooling occupies 10-12 minutes. Over the next 10 minutes 
the nasopharyngeal, oesophageal, and mixed venous temperatures drift together at $28^{\circ} \mathrm{C}$. Considerable variation in these cooling rates occurs with the physique and age of the patients, and experience is essential for accurate control of cooling.

While cooling is in progress the left atrial vent is placed in the left atrium via the atrial appendage, and is connected to a small reservoir to which is connected the left atrial tubing from the machine. When ventricular fibrillation occurs the vent is opened to prevent overdistension of the heart. It is essential to observe the level of blood, as a falling venous pressure may allow the left heart to fill with air if the vent is not clamped. A $U$ tube below the level of the left atrium will prevent this (Wonham, 1961). Fibrillation usually occurs at $28^{\circ} \mathrm{C}$., but hypoxia of the tissues is prevented by changing to total bypass.

Total bypass is begun by occluding the caval snares, thus directing all venous return to the machine. An alternative technique cannulates the right atrium only and clamps the pulmonary artery to achieve total cardiopulmonary bypass. This is useful in cases of aortic stenosis and reduces the operating time. The venous clamp at the machine is now opened fully and the output is adjusted to the venous return. The aorta is now clamped and the pericardium is packed with ice-saline mush to induce local hypothermia to 15 to $18^{\circ} \mathrm{C}$. This affords the operator the opportunity of an hour to an hour and a half's work on a dry, still heart (Ross, 1961a). If desired the aortic clamp may be released to flush the coronary vessels of accumulating acid metabolites, although in general anaerobic metabolism goes on slowly in heart muscle. A further advantage of the dry arrested heart is the reduction in suction need and a consequent reduction in blood trauma and haemolysis.

Once total bypass has been started a slight drop in mean arterial pressure to 70 to $80 \mathrm{~mm}$. $\mathrm{Hg}$ is usual, but this quickly stabilizes at 80 to $100 \mathrm{~mm} \mathrm{Hg}$. After 30 to 40 minutes of total bypass the mean arterial pressure commonly rises to 120 to $150 \mathrm{~mm}$. $\mathrm{Hg}$. This may be a reflection of return of vasomotor tone with adaptation to hypothermic conditions, as it is thought vasomotor paralysis is an early effect of this method of body cooling (Ross, 1961b). (Compare surface cooling where peripheral vasoconstriction is an early feature (Kenyon and Cooper, 1956).)

Although at $30^{\circ}$ C. a flow of 1.2 litres/square metre/minute is thought to be adequate for metabolic requirements it is our practice to perfuse the patient at a flow compatible with unobstructed venous return. It is clear that hypoxic acidosis is minimized by high flows of well-oxygenated blood (Clowes, Neville, Sabga, and Shibota, 1958).

When the operation is completed rewarming is started slowly. One should try to reach $31^{\circ} \mathrm{C}$.$32^{\circ}$ C. or a flow compatible with good oxygenation for the temperature by the time the surgeon is ready to defibrillate the heart. The aortic clamp is released early in rewarming to raise the cardiac temperature.
If the aorta has been incised coronary artery perfusion is performed at 300 to $480 \mathrm{ml}$./minute while the aorta is sutured. Before cardiac action has restarted (spontaneously or by defibrillation) the superior vena caval snare is released to allow the heart to fill. At this stage air is removed from each cardiac chamber by aspiration after elevating the heart to collect bubbles at the apex. When good cardiac action is apparent the inferior vena caval snare is released. The pump operator now reduces venous return into the machine and arterial output to the patient to allow the heart to take an increasing amount of work. Heating is continued over this period. A flow of a litre a minute is maintained until the nasopharyngeal temperature has reached $35^{\circ} \mathrm{C}$. If cardiac conditions are stable the patient is now weaned from the machine. Failure of the heart is quickly reflected by a rise of left atrial pressure or the return of ventricular fibrillation. In straightforward cases weaning lasts two to three minutes. Once bypass is stopped careful attention is paid to the arterial and right atrial pressure. Blood is given to the patient from the machine until the arterial pressure is normal and the atrial pressure is not above $15-20 \mathrm{~mm}$. $\mathrm{Hg}$. When the patient is maintaining these conditions the left atrial vent is removed, then the caval cannulae. The arterial cannula is removed when it is clear that haemorrhage is controlled and there is circulatory stability. Polybrene (hexadimethrine bromide) is given in a dose of $2 \mathrm{mg}$. of Polybrene per $\mathrm{mg}$. of heparin to neutralize the anticoagulant before removing the arterial cannula. Compensation is made for the heparin in the blood transfused from the machine. It is occasionally necessary to go back on bypass if, for example, severe aortic regurgitation has occurred, and it is thus essential not to remove cannulae nor neutralize the heparin until the circulatory conditions are quite stable.

\section{Technical Difficulties}

These are overfilling, emptying, foaming, and miscellaneous.

OverfiLling.-This can result from: (a) High venous pressure early in bypass; $(b)$ the opening of a distended cardiac cavity, e.g., the left atrium in mitral regurgitation may contain up to $1,500 \mathrm{ml}$. of blood; (c) operator error in bleeding the patient without opening the arterial line or leaving the recirculating line open, thus bleeding the patient from both veins and artery ; $(d)$ incorrect setting of the roller heads reducing occlusiveness. Back bleeding occurs during the non-occlusive phase of the pump.

On one occasion the cooling circuit was switched on before bypass and effectively froze the blood in the heat exchanger and the patient bled into the machine. This was corrected by excluding the heat exchanger and the perfusion was successfully conducted at normal temperature.

Overfilling is minimized by careful attention to the venous outflow, graduated suction by the surgeon in 
the face of a heavy flow, and the use of the bleeding-off bottles already described. This blood is subsequently returned to the patient via the machine during or after bypass. The danger in overfilling is that of blood reaching and being whipped into foam by the centre spindle of the oxygenator.

EMPTYING.-This can be catastrophic, as an air embolus under pressure will result. Vortices do not occur at the outflow end of the oxygenator due to the mixing effect of the discs. Emptying occurs as a result of :

Failing Venous Return.-This may be due to poor placing of the cannulae with the snares occluding the cavae proximal to the cannula; kinking of the venous lead as it leaves the chest or table; occlusion of the venous lead by pressure of the assistant's arm or leg. This risk is reduced by using moderately rigid tubing for the venous line and taking care in positioning the cannulae. An unrecognized left superior vena cava may confuse and cause poor venous return as a large volume of blood will return via the coronary sinus. The cannulae may have their ends occluded by a high negative pressure sucking on the veins. This may occur with small children and is corrected by lowering the table.

Failure to Replace Blood Lost.-Undetected steady loss may occur into the pleural cavities when the heart is open, or it may be sucked away by the ordinary sucker when used to remove the melted saline mush. It is essential that the pump operator be able to scan the whole operating field and draw the surgeon's attention to this hazard, as the surgeon in his concentration on the cardiac lesion may overlook it.

Retroperitoneal Leak.-This or retrograde aortic dissection from the arterial cannula may occur if the securing tapes are not tight and may be obscured by the drapes covering the arterial line. Occasionally intimal dissection may occur, and unless the possibility is kept in mind a dissecting aneurysm may result.

Vasodilatation.-This occurs during rewarming as acid metabolites are mobilized and causes an increased vascular bed of up to $1,500 \mathrm{ml}$., but is not often a problem as it occurs at a period when bypass is about to be terminated.

Splitting of Tubing.-If excess pressure is generated in the outflow line as a result of an obstruction, or from the use of too small a cannula for the required flow, the rubber tubing may distend and split. To overcome this crisis a spare arterial set is maintained sterile in the theatre at all times.

Several centres use electronic monitors which turn the machine off if the level in the venous reservoir drops below a sensing device. It is felt the best sensing device is a well-trained, attentive pump operator in co-ordination with his surgeon.

FoAMING.-This can occur if the machine becomes overfilled and blood reaches the centre spindle, or if "dished" discs are used reducing the inter-disc space to less than $4 \mathrm{~mm}$. A film forms between two discs and is propagated along the chamber. Occasionally bubbles enter the oxygenator if the level in the venous reservoir drops below the entry port. Some bubbling occurs in the venous reservoir due to turbulence from the venous return. Excessively strong suction can be more dangerous and may fill the coronary reservoir with fine froth, some of which may pass into the machine. Large bubbles tend to break up. Foaming is a rare complication of perfusion with this machine.

Miscellaneous.-Failure to maintain a perfusion pressure may arise from failure to recognize a persistent ductus arteriosus, or from severe aortic regurgitation, or, in cases of Fallot's tetralogy, bronchial artery run-off may simulate a ductus with sequestration of blood in the lung fields. If a ductus is recognized it must be divided. In most cases it is excluded pre-operatively by a retrograde aortogram. Aortic regurgitation may be controlled by clamping the aorta followed by repair of the valve. In Fallot's tetralogy the patient is protected against a low pressure by the perfusion of blood of high oxygen saturation to tissues adapted to hypoxia, i.e., oxygenation will compensate for a short while for hypotension.

Failure of the heating and cooling circuits is rare in these reliable units. In the event of failure of either, hot or cold water may be funnelled manually into the heat exchanger.

In the case of a power failure, each pump is provided with lugs to engage a hand crank. This has not, so far, been needed.

Clotting in the machine has occurred once when Polybrene was applied locally to staunch haemorrhage from oozing surfaces before finishing bypass, the coaguable blood being returned to the machine by suction. This was an accepted risk in this subsequently fatal case of ruptured aortic aneurysm. Once the heparin antagonist has been given the machine suction is switched off.

The arterial cannula may become disconnected, and care should be taken to switch off the machine before clamping the arterial tubing as further complications may arise from the sudden high pressure generated, e.g., tubes may split.

In one case incorrect filter assembly permitted the fine wire mesh to occlude the arterial outflow. A deposit of fibrin and cellular debris occluded the arterial line. This was corrected by dividing the recirculating line and connecting it to the arterial line. The filter design has been modified to exclude this hazard.

\section{Discussion}

It is felt that this machine presents advantages over existing machines that make it reasonable to introduce it into a field already crowded with similar apparatus all of which possess advantages, at least in the hands of their designers.

Discs.-The use of discs offers a large oxygenating surface in a minimum of space. 
Oxygenation is $100 \%$ up to flows of $2,800 \mathrm{ml}$./ minute as used at present. Coupling a second set of discs in parallel into the circuit will double the capacity. The discs have a low propensity for foaming, and the absence of churning reduces haemolysis.

HYPOTHERMIA.-The protection of hypothermia with the advantage of a dry, still heart presents many attractions to the cardiac surgeon. Reduction in metabolic requirements $\left(50 \%\right.$ at $30^{\circ} \mathrm{C}$.) with the lower flows required reduces the risks of foaming and haemolysis and allows adequate body perfusion. Hypothermia has been fully discussed by Cooper and Ross (1960), Ross (1954), Bigelow, Callaghan, and Hopps (1950), Delorme (1952), and many others.

Priming Volume.-The reduction of priming volume to $2,000 \mathrm{ml}$. with one oxygenator compares more favourably with many described machines using up to 4 litres. This will reduce the strain on blood banks, especially in countries where blood is not as readily available as in England.

VERSATILITY.-The incorporation of a heating and cooling circuit with a heat exchanger of high efficiency allows a wide choice of techniques from normothermic procedures to those of profound hypothermia at $15^{\circ} \mathrm{C}$. Cooling is rapidly achieved and if during the procedure added protection is desired it is easy to drop the temperature further. Warming likewise is rapid and it is possible to return easily to cooling should it become necessary. Inclusion of a second oxygenator allows full normothermic flows. The size of the patient does not present a problem, as children are perfused using the smaller lung incorporating 60 discs. This reduces the priming volume by 500 $\mathrm{ml}$. and allows satisfactory oxygenation and control of $p \mathrm{H}$ and $\mathrm{PCO}_{2}$ up to $1,500 \mathrm{ml}$./minute. Very small children and infants are perfused on the machine described by Ross (1960b).

CONTROL.-This is readily maintained on the accessible panels on the machine. Driving mirrors allow the operator to see the levels in the machine from a central position. The gear box included in the drive pump allows a wide range of flows with accurate control of the rate of delivery, monitored by the revolution counter on the panel.

Maintenance.-The ease with which the set can be dismantled and the lack of crevices allow thorough cleaning. One technician (without special training) is employed full time under the supervision of the theatre sister to clean and prepare the sets, prepare the machine for theatre, and assist with the perfusion. It should be possible to train a technician to conduct the perfusion under the control of the anaesthetist.

CoMPaCTNESS.-The machine is relatively small and self-contained. The reduction in personnel to conduct the perfusion will be a saving in staff in those countries where trained staff are at a premium.

QuiETNESS.-While running, the machine emits a low-pitched, unobtrusive hum which does not add significantly to the already high background level of noise that seems to prevail in a cardiac operating theatre. This reduces strain and fatigue induced in the surgeon by a sustained level of noise.

SAFETY.-With foaming a rare occurrence and no problems in maintaining an oxygenating surface the well-filled machine has a high index of safety. Provided the operator is aware of the hazards outlined above and the means of correcting them, danger to the patient from a technical source is minimal. It is disappointing, to say the least, to perform adequate surgery and lose the patient from a technical misadventure.

OXYGEnATION.-At flows up to $2,800 \mathrm{ml}$. per minute oxygenation is $100 \%$ irrespective of the length of bypass. This has been investigated in a series of cases (Molloy, 1961b). An increase in the arteriovenous oxygen difference above $30 \%$ is uncommon and usually occurs on coming off bypass when stagnant blood is being mobilized from the muscles and oxygen utilization is increasing.

MoBILITY.-The all-inclusive nature of the machine allows its ready transfer from preparation room to theatre and reduces the need for large masses of apparatus in the theatre. Although heavy it is easy to manage.

Pumps.-The de Bakey type pump has been found reliable and has a low haemolysis rate (Cahill and Kolff, 1959). The pumps are robust and hard wearing, easily set to be occlusive, and reliable. Using tubing of uniform bore the stroke volume per revolution is easily assessed. This allows accurate blood replacement after bypass in measured quantities should it be required as well as rendering calibration accurate and simple. Observations of line and radial artery pressure during perfusion indicate a pulse pressure of 10 to $15 \mathrm{~mm}$. Hg. This is thought to have some influence on the maintenance of normal vasomotor tone and tissue perfusion.

Metabolic Maintenance.-Using 97\% oxygen and $3 \%$ carbon dioxide as the chamber atmo- 
sphere, it can be demonstrated that $p \mathrm{H}, \mathrm{PCO}_{2}$, and plasma bicarbonate are maintained at physiological levels (Molloy, 1961b). A respiratory acidosis induced in a child was readily corrected during partial bypass by hyperventilation.

Although at present we do not add bicarbonate to the priming blood, there may be a case for so doing as it is uniformly acid $\left(p \mathrm{H} \mathrm{6.8-7.1,} \mathrm{PCO}_{2}\right.$ $100+\mathrm{mm}$. Hg, bicarbonate 15-18 m.mol./litre). Perhaps $10 \mathrm{~m} . \mathrm{mol}$. per litre added to the priming blood would save some strain on the base reserves should acidosis develop.

Flow requirements in these patients are based on a metabolic reduction of $50 \%$ at $30^{\circ} \mathrm{C}$. (Adolph, 1956), although Clowes et al. (1958) have shown in dogs that oxygen consumption is reduced to $70 \%$ of normal with reduction of body temperature to $30^{\circ} \mathrm{C}$. This gives a flow of 1.2 litres/sq. metre/minute as a minimum flow at this temperature, but it is our policy to give as large a flow as is compatible with good oxygenation and venous return. In addition most patients are perfused at $28^{\circ} \mathrm{C}$. as the authors believe that the extra $2^{\circ} \mathrm{C}$. confer added protection without increasing the hazards of hypothermia.

Acidosis is clearly related to low flow, hypoxia, and a low blood pressure (Litwin, Panico, Rubini, Harken, and Moore, 1959). A mean pressure of less than $50 \mathrm{~mm}$. $\mathrm{Hg}$ for more than 15 minutes is thought to contribute to post-operative renal disorders, as the increasing viscosity of the blood and renal vasoconstriction, with cold, or reflexly in response to lowered left atrial pressure, may raise the capillary opening pressure from a normal of $32 \mathrm{~mm}$. $\mathrm{Hg}$ to $50 \mathrm{~mm}$. $\mathrm{Hg}$ (Hudson, 1959).

Hypocapnia causes severe cerebral vasoconstriction, and although, if cerebral anoxia occurs, the rapid formation of acid metabolites will override this constriction it is better to maintain an adequate cerebral perfusion with arteriolar dilatation than risk cerebral ischaemia. This is contrary to views expressed earlier (Molloy and Griffiths, 1961 ; Viles, Ankeney, and Cox, 1960), but is in accord with most published opinion (Sokoloff, 1960).

Measurements of $\mathrm{PCO}_{2}$ taken during bypass indicate that once cooling is completed a reduction in carbon dioxide percentage to 1.5 in the oxygenator gas may prevent the development of a respiratory acidosis which will aggravate metabolic acidosis should it occur. Once rewarming is started the carbon dioxide percentage should be restored to $3 \%$ to aid vasodilatation, especially cerebral and renal, and to compensate for the hypocapnia induced by vigorous ventilation at a stage when the lungs are stiff and difficult to inflate. If smaller children are perfused using the 100 disc cylinder the carbon dioxide percentage should not be lowered as respiratory alkalosis is quickly engendered.

The results of perfusions using the prototype of this machine are discussed elsewhere (Molloy, 1961a). The technique described has been found safe and reliable with a minimum of post-operative complications attributable to perfusion.

\section{SUMMARY}

A cardiopulmonary bypass machine is described, noting its construction, technique of assembly, maintenance, and use.

The principle is that of disc oxygenation incorporating a simple hypothermia unit. The advantages of the machine are noted.

Various technical and physiological factors inherent in extracorporeal circulation are reviewed.

We wish to thank Sir Russell Brock and Mr. Donald Ross, who have operated on the patients perfused. The Department of Medical Illustration has kindly supplied the figures. Mr. I. Chard and Mr. G. H. Samuels have given many hours to careful cleaning and preparation of the machine and sets and long hours assisting in the theatre.

The machine is available, as described, from Cardiac Recorders, Ltd., 377 City Road, London, E.C.1, who have given much assistance with technical details.

\section{REFERENCES}

Adolph, E. F. (1956). In The Physiology of Induced Hypothermia. Ed. by R. D. Dripps, p. 44. Nat. Acad. Sci., National Research Council, Washington, D.C.

Bigelow, W. G., Callaghan, J. C., and Hopps, J. A. (1950). Ann. Surg., 132, 531

Bloom, A. L. (1961). Brit. med. J., 2, 16

Bracken, A., Wilton-Davies, C. C., and Weale, F. E. (1960). Guy's Hosp. Rep., $109,75$.

Cahill, J. J., and Kolff, W. J. (1959). J. appl. Physiol., 14, 1039.

Clowes, G. H. A., Neville, W. E., Sabga, G., and Shibota, Y. (1958). Surgery, 44, 220.

Cooper, K. E., and Ross, D. N. (1960). Hypothermia. Cassell, London.

Delorme, E. J. (1952). Lancet, 2, 914

Delorme, E. J. (1952).
Hudsoncet, $2,914$.
Hud. A. (1959). Brit. J. Anaesth., 31, 378.

Kenyon, J. R., and Cooper, K. E. (1956). Proc. 20th Int. Physiol. Congr., Brussels, 1956.

Kittle, C. F., and Eilers, R. (1960). Arch. Surg. (Chicago), 81, 179 Litwin, M. S., Panico, F. G., Rubini, C., Harken, D. E., and Moore F. D. (1959). Ann. Surg., 149, 188.

Molloy, P. J. (1961a). Thorax, 16, 335. (1961b). In preparation.

and Griffiths, P. D. (1961). Guy's Hosp. Rep., 110, 99.

Ross, D. N. (1954). Ibid., 103, 116. (1960a). Brit. med. J., 2, 571

(1960b). Lancet, 2, 1064

(1961a). Ibid., 2, 293.

(1961b). Personal communication.

Smith, W. W., Brown, I. W., Young, W. G., and Sealy, W. C. (1959). $J$. thor. cardiovasc. Surg., 32, 573.

Sokoloff, L. (1960). Anaesthesiology, 21, 664.

Viles, P. H., Ankeney, J. L., and Cox, L. M. (1960). J. thor. cardiovasc. Surg., 39, 619.

Wonham, J. D. (1961). Personal communication. 